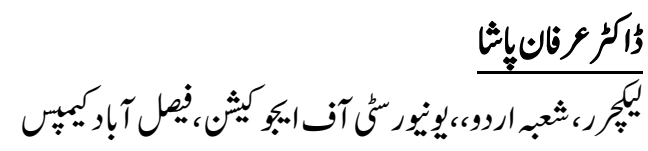

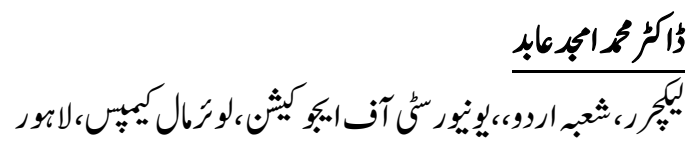

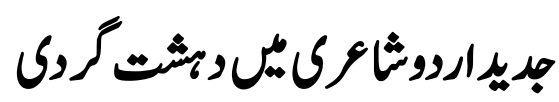

\title{
Dr. Irfan Pasha
}

Lecturer, Department of Urdu, University of Education, Faisalabad Campus.

\section{Dr. Muhammad Amjad Abid}

Lecturer, Department of Urdu, University of Education, Lower Mall Campus, Lahore.

\section{Terrorism in Modern Urdu Poetry}

TERRORISM is the most influencing factor not only in our social set up but an important literary theme as well world over. Urdu literature is also much to do with the contemporary human problems. With the stat of the 20th century a wave of terrorism is spread round the globe. Pakistan is badly affected by this catastrophe. Urdu poets have depicted this matter to a large extent in modern poetry of the new millennium. This article deals with the presentation of terrorism in Urdu poetry by our intellectuals and poets of new thoughts. They feel themselves the part and parcel of the world intelligentsia and fully condemn the phenomenon of terrorism.

Keywords: Terrorism, Influencing, Social, Literary, globe, Poetry.

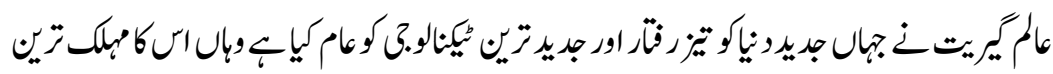

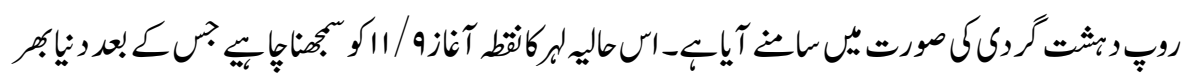

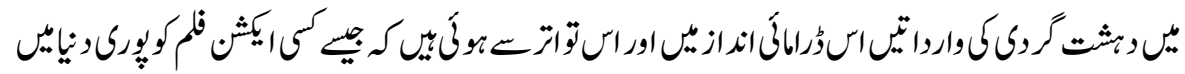

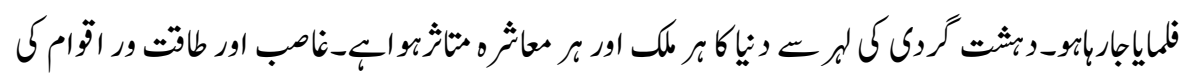

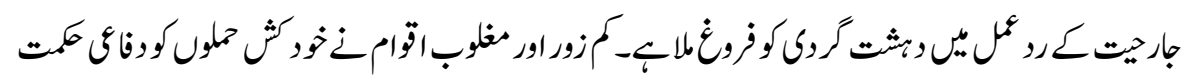




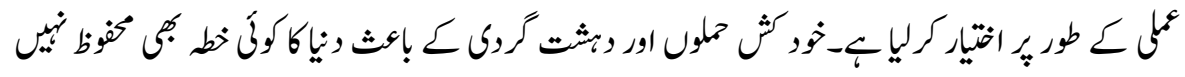

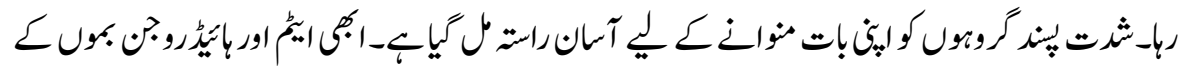

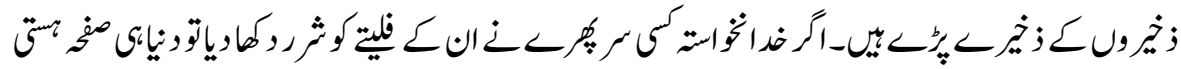

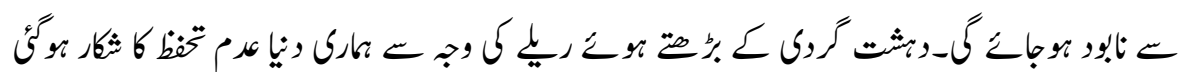

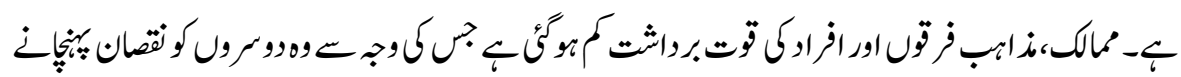

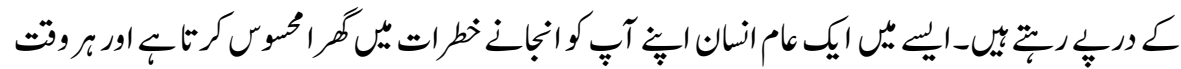

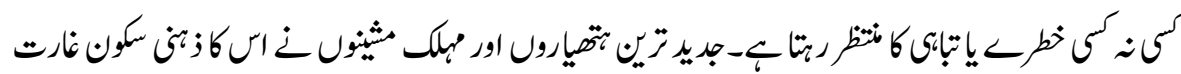

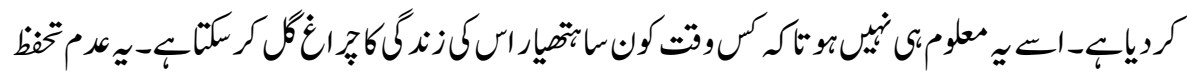

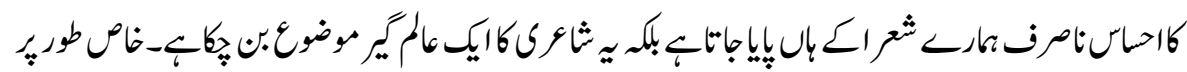

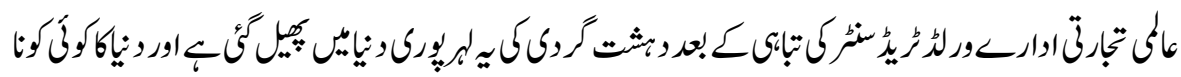

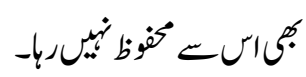

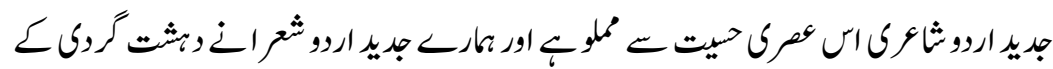

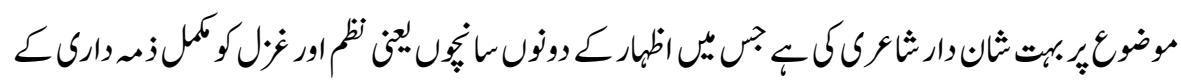

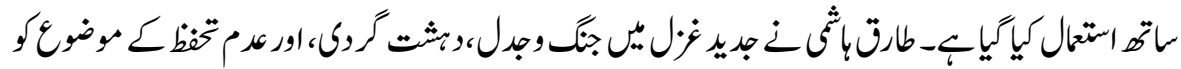

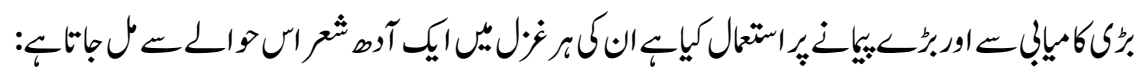

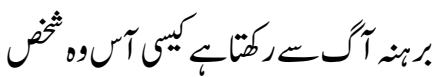

$$
\begin{aligned}
& \text { (1) }
\end{aligned}
$$

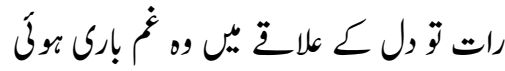

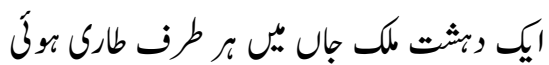

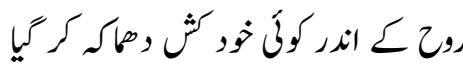

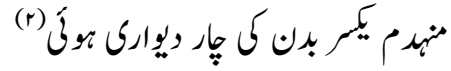




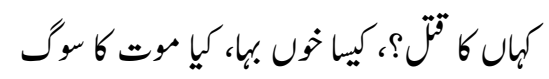

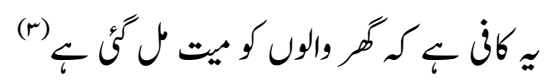

آس تكّلى

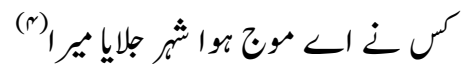

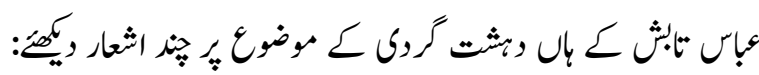

تو

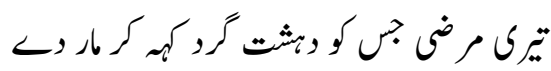

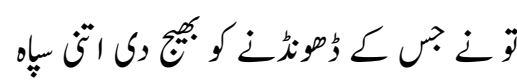

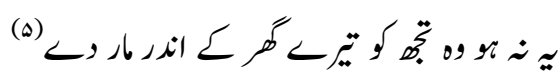

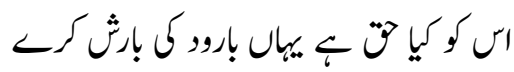

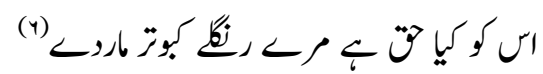

منور آفاق كمئ بي:

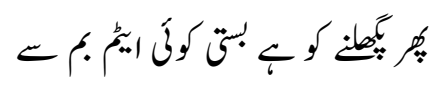

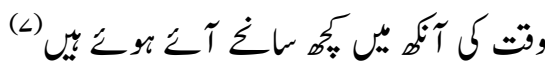

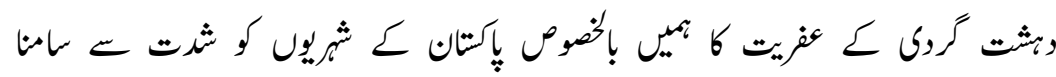

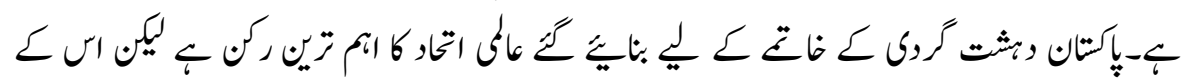

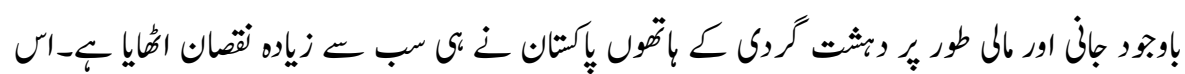

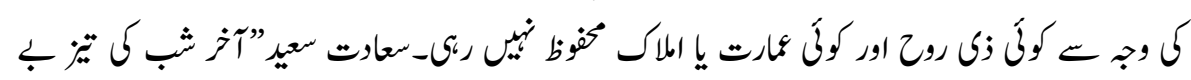

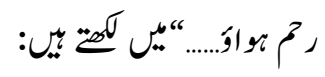

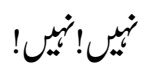

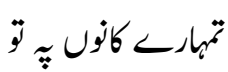




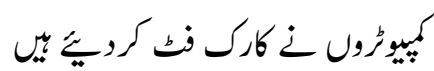

$$
\begin{aligned}
& \text { تئيول ير لوب كن ثيتزيال سجارك بيل } \\
& \text { تمبه كيا معلوم جبر كم تواؤ } \\
& \text { تمبه كيا معلوم! }
\end{aligned}
$$

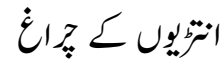

$$
\begin{aligned}
& \text { : } \\
& \text { اوضا جنمول كم رُاليول كـ } \\
& \text { (1) ? ? ? }
\end{aligned}
$$

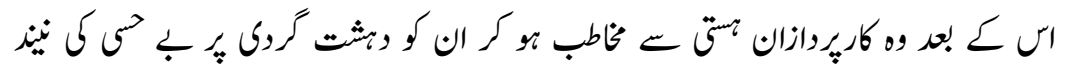

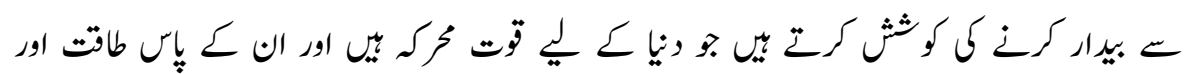

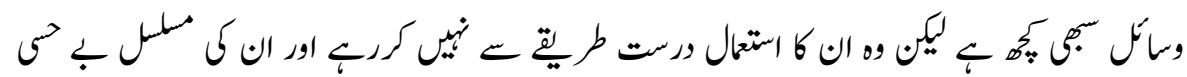

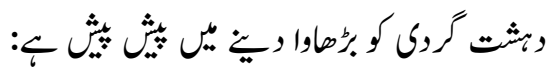

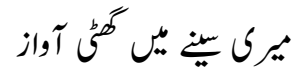

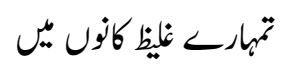

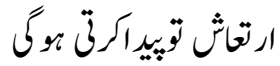

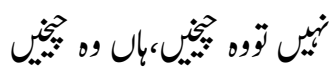

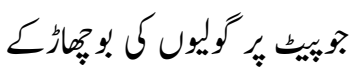

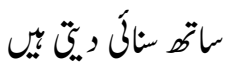

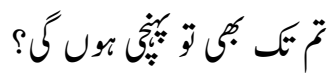

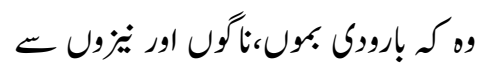

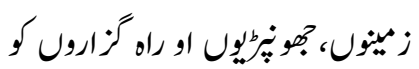

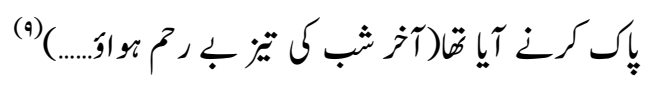




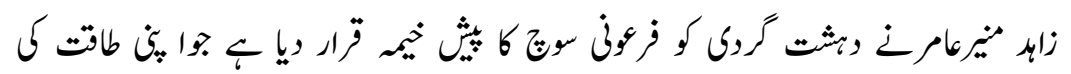

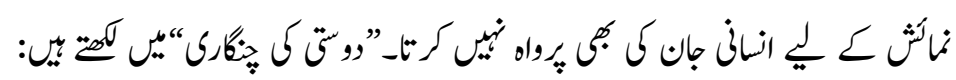

ثعله وثراس ك

موبوك وصابن كر

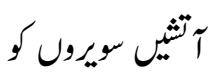

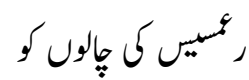

جر ك مثار كو

ظظلم

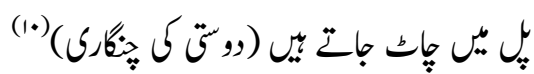

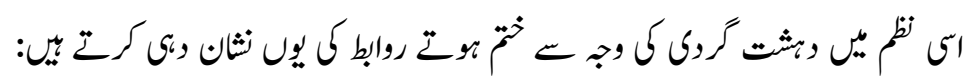

آثثيل بويرول بيل

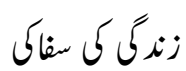

آنيخ روابط كن

(11)

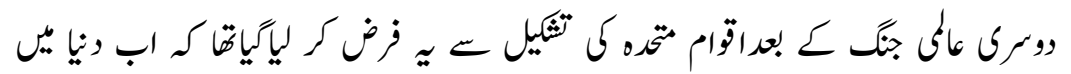

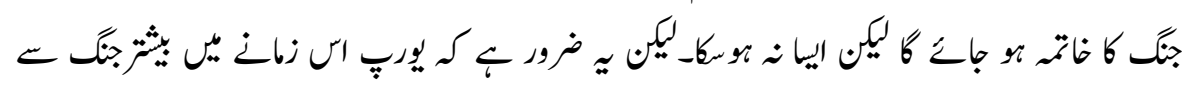

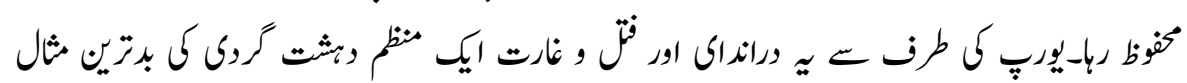

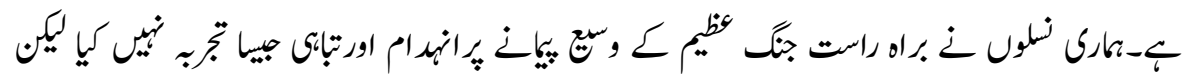

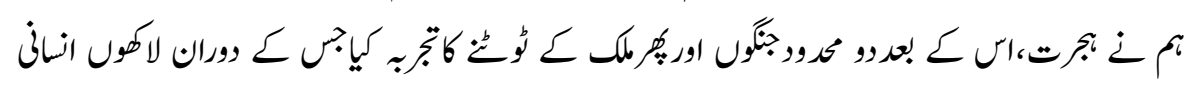

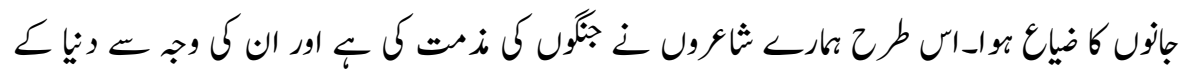

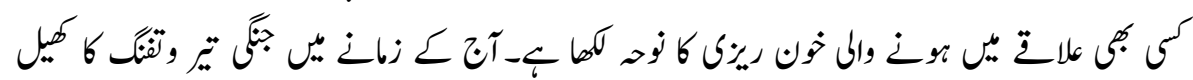

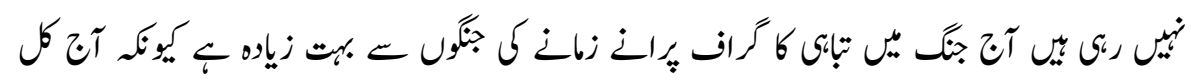




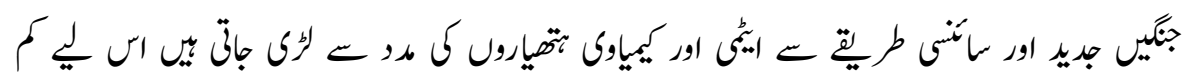

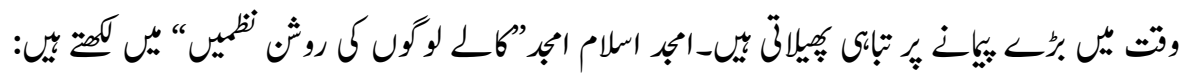

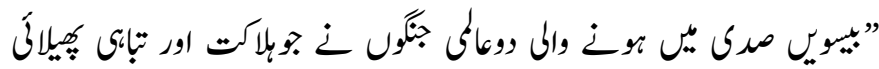

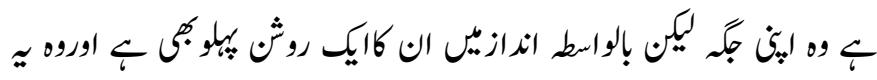

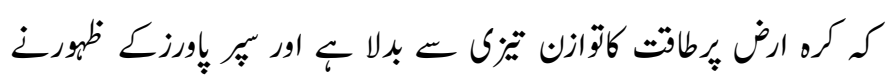

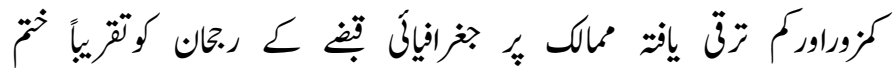
كرويإ_ (ir)،

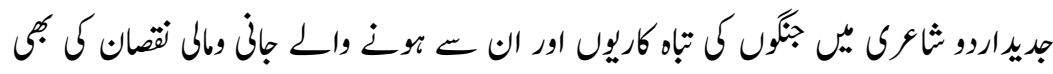

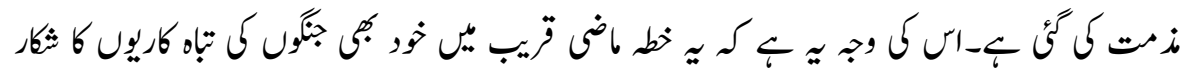

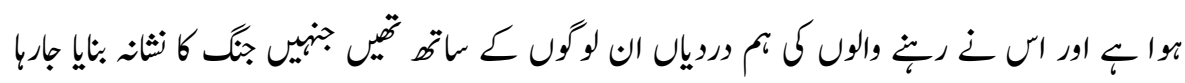

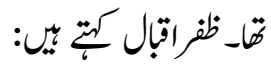

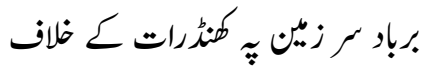

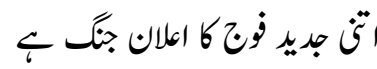

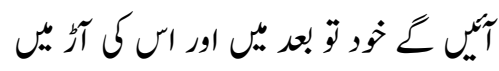

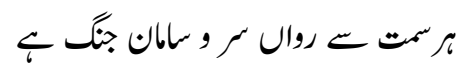

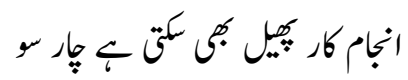

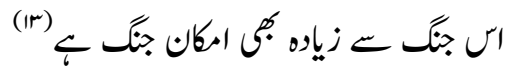

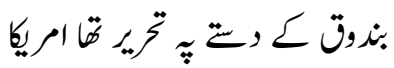

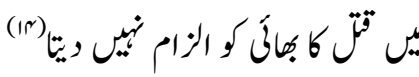

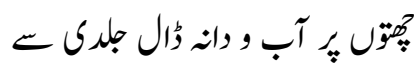

$$
\begin{aligned}
& \text { فضا بمبار طيارول ك نال بـ }
\end{aligned}
$$




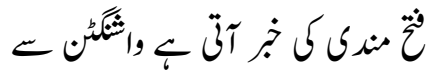

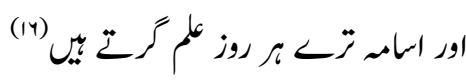

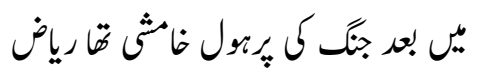

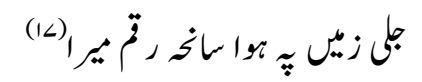

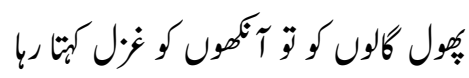

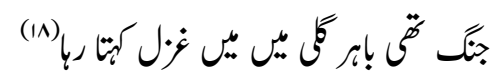

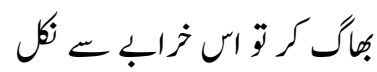

$$
\begin{aligned}
& \text { (19) }
\end{aligned}
$$

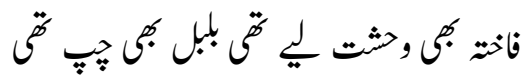

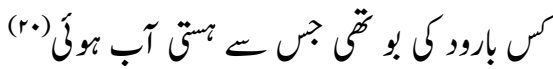

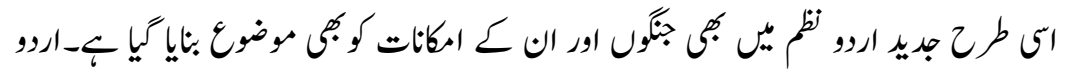

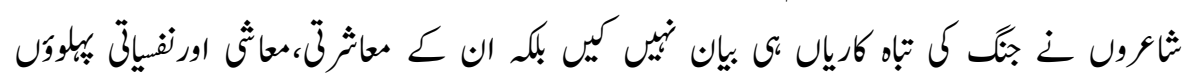

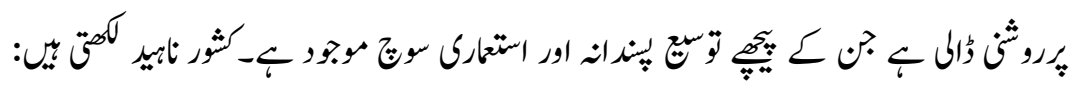
سمورى كالمالو بي

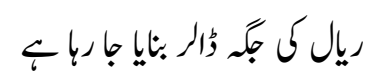

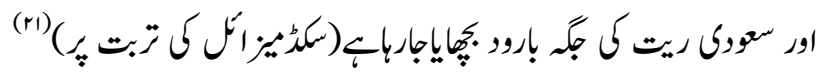

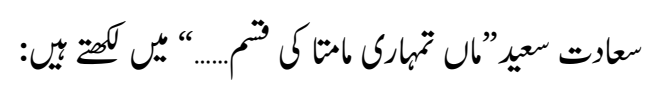

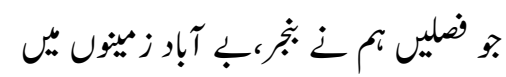




$$
\begin{aligned}
& \text { آخ جمول كم كمار }
\end{aligned}
$$

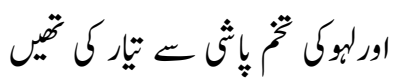

$$
\begin{aligned}
& \text { انبنى تور كنول ك وارئ }
\end{aligned}
$$

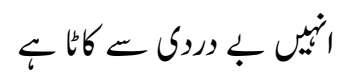

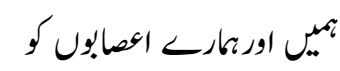

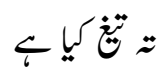

$$
\begin{aligned}
& \text { مرف ايكس تبل }
\end{aligned}
$$

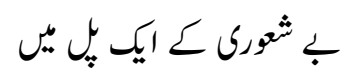

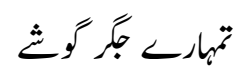

$$
\begin{aligned}
& \text { همارى فصلي }
\end{aligned}
$$

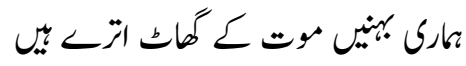

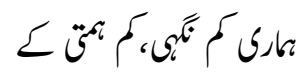

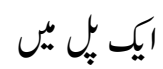

$$
\begin{aligned}
& \text { ماراتز كام } \\
& \text { كروزول انانولكا } \\
& \text { تز كام كواب }
\end{aligned}
$$

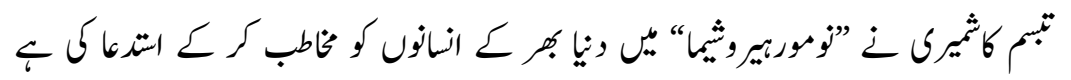

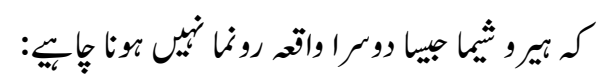

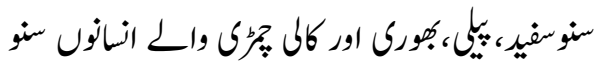

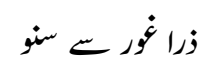

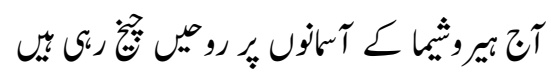

$$
\begin{aligned}
& \text { "ونمورتيروشيما" }
\end{aligned}
$$

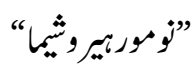


ISSN (Print): 2709-9636 | ISSN(Online) : 2709-9644 | ISSN-L : 2709-9636

家

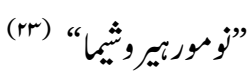

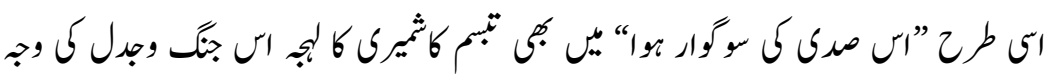

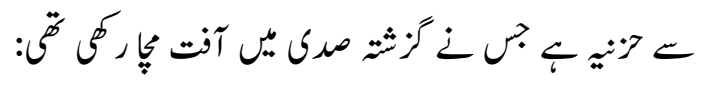

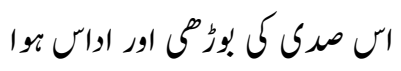

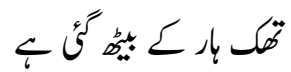

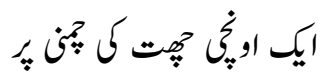

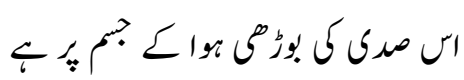

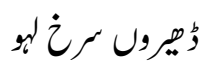

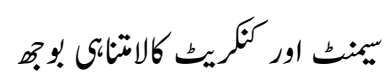

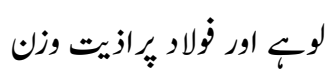

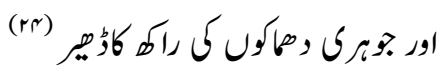

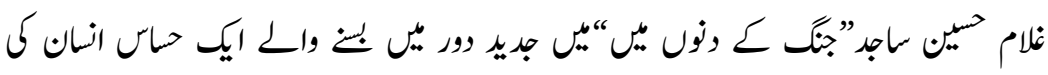

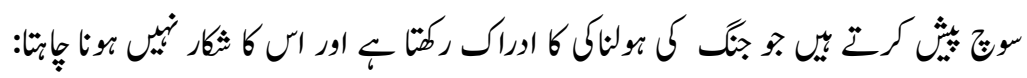

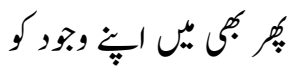

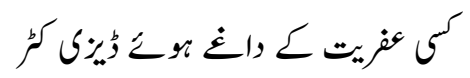

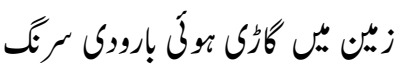

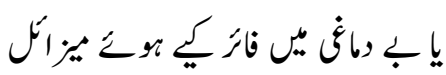

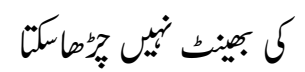

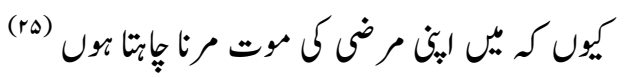

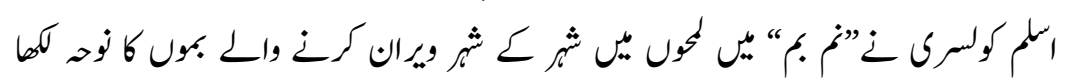

ايكب بمبار

ايكس لئحين

$m$ 


$$
\begin{aligned}
& \text { كى آباد ثم ك، يونى }
\end{aligned}
$$

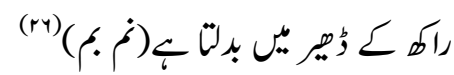

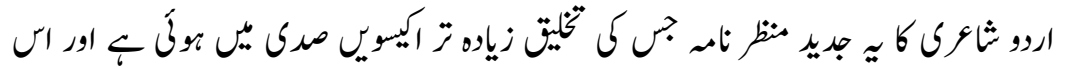

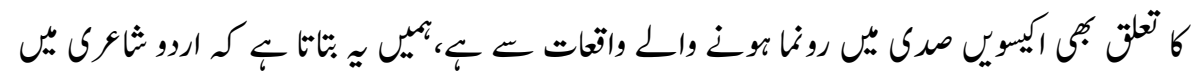

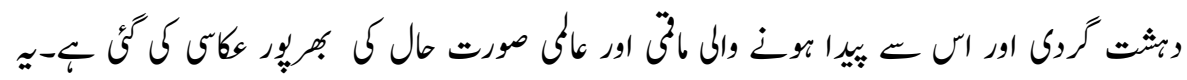

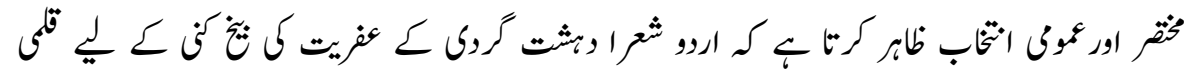

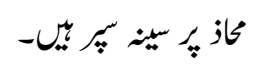

\section{حوال جات}

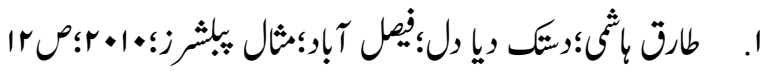

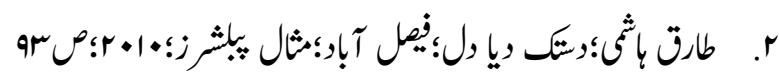
r. r.

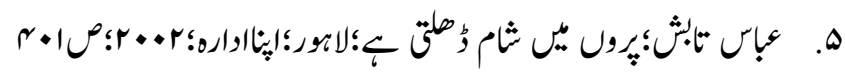

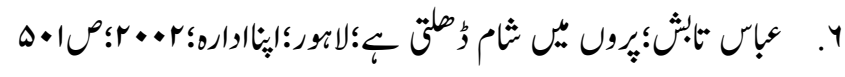

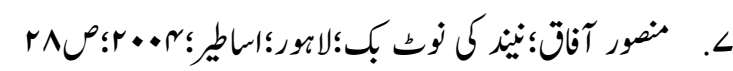

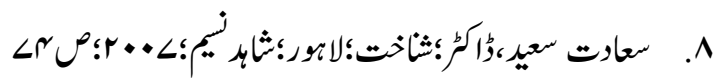

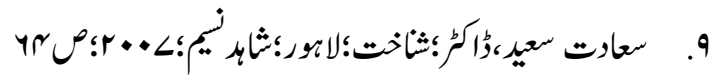

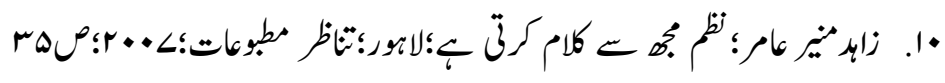

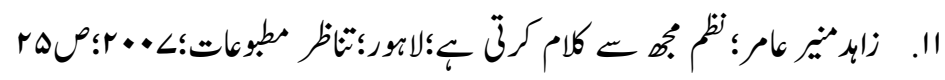

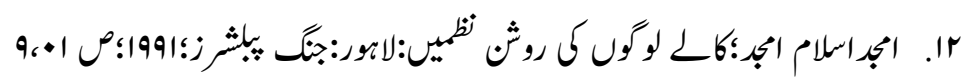

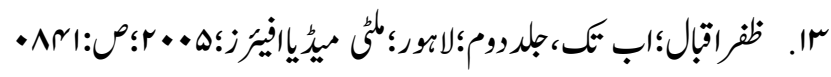
Ir

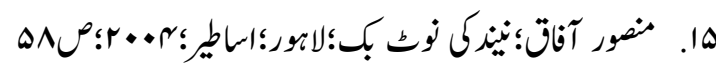




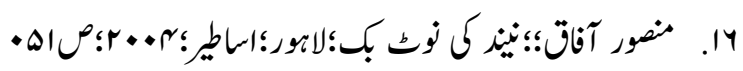

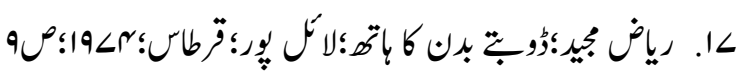

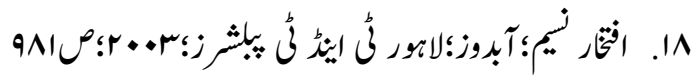

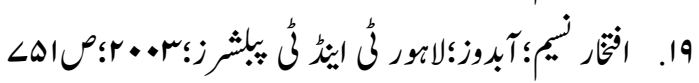

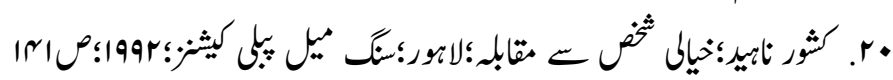

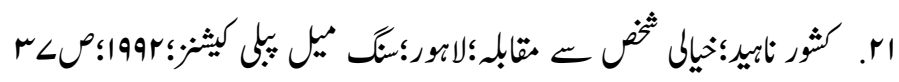

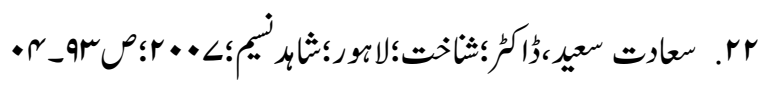

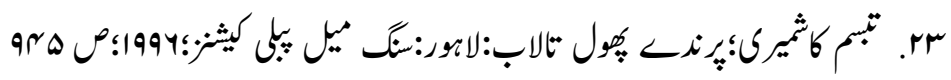

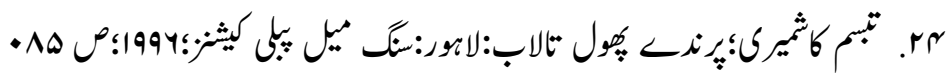

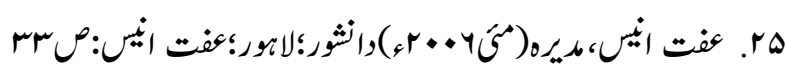

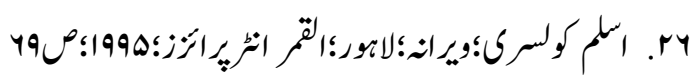

